\title{
Evaluation Method of Rolling Bearing Quality (Part II : Experiment)
}

\author{
Xintao Xia ${ }^{1, a}$, Bin Liu ${ }^{1, b^{*}}$, Yunfei $\mathrm{Li}^{1, c}$, Zhen Chang ${ }^{1, d}$ and Wenhuan Zhu, ${ }^{1, e}$ \\ ${ }^{1}$ Mechatronical Engineering College, Henan University of Science and Technology, Luoyang \\ 471003, China

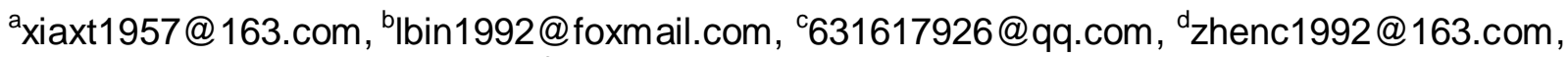 \\ ezhuwenhuan0916@126.com \\ *The corresponding author
}

Keywords: Rolling bearing; Bearing vibration quality; Grey system theory; Correlation degree

\begin{abstract}
Rolling bearings is the basic connection parts of machinery, whose quality plays an irreplaceable role for the normal operation of machinery and equipment. Therefore, it is particularly important to make an evaluation of bearing quality. In this paper, factors affecting the machining precision of the tapered roller bearing vibration quality were analyzed using the grey system theory together with the classical statistic theory. The test object is 30204 tapered rolling bearing. It is obtained that the roller spherical runout range, the outer raceway angle error, the average of roller roughness and the roller convexity range are the main factors which affect the tapered roller bearing vibration quality. In the machining process, due to the controllable of these factors the control of finished bearing quality will come into reality in parts machining process.
\end{abstract}

\section{Introduction}

Rolling bearing quality has received widespread attention. Many scholars have conducted relative research and a number of new bearing fault diagnosis methods have been proposed [1-3]. The reference [4] studied the life and reliability of rolling bearing after repair, and made an assessment of the quality of rolling bearing after maintenance. Z.Q. Yu analyzed the fatigue life of rolling bearing in the motor under grease lubrication [5]. S. Söchting simulated and evaluated the vibration of ball bearing friction and lubrication performance impact in space applications [6]. These studies are of great help and have an important guiding significance for rolling bearing quality improvement.

However, there is lack of research data due to the specificity of the test objects in reality. This kind of research is mostly small sample problem [7]. The lack of test samples and test data results in the fact that it is hard to solve this kind of problem using only the classical statistical theory. This paper is mainly based on 30204 tapered roller bearings to get all the data needed, which are analyzed by combining the grey system theory $[8,9]$ and the classical statistical theory. A model for parameter estimation and inference of tapered roller bearings quality was established, and the factors of vibration quality were analyzed to obtain a control method of quality.

\section{Experimental Research and Data Analysis}

The experimental study on the factors influencing the bearing vibration quality, The C\&U GROUP of 30 sets of 30204 tapered rolling bearing samples were chosen as research objects. The tapered roller bearing vibration acceleration and 32 selected parameters were measured. And the relationship between the parameters and bearing vibration was studied to seek methods to control the rolling bearing quality.

In order to facilitate research, define the vibration acceleration value as $Y$, and other symbols are described in Table 1, during which the (A) are on behalf of roller parameters average and the (V) are on behalf of poor roller parameter values.

In the production site, randomly select and number 30 bearing samples, and obtain the vibration acceleration of rolling bearing after measurement 
$Y=(46,47.7,47.7,47,48,47.7,48,47.7,47.7,46.7,47.7,44,46,46.7,48,45,47,45.3,45.7$, $45.3,47.3,48,47,47.3,47.3,47,47.3,46.7,44.6,47.3)$

Table 130204 roller bearing quality factors symbols and their meanings [ $\mu \mathrm{m}]$

\begin{tabular}{cccccc}
\hline Symbol & Meaning & Component & Symbol & Meaning & Component \\
\hline$X_{1}$ & $D_{w}(\mathrm{~A})$ & roller & $X_{17}$ & $K_{\mathrm{i}}$ & inner race \\
$X_{2}$ & $\Delta 2 \Phi(\mathrm{A})$ & roller & $X_{18}$ & $S_{\mathrm{di}}$ & inner race \\
$X_{3}$ & convexity (A) & roller & $X_{19}$ & $\Delta 2 \beta$ & inner race \\
$X_{4}$ & roundness (A) & roller & $X_{20}$ & $L_{\mathrm{i}}$ & inner race \\
$X_{5}$ & waviness (A) & roller & $X_{21}$ & inner raceway roundness & inner race \\
$X_{6}$ & roughness (A) & roller & $X_{22}$ & inner raceway waviness & inner race \\
$X_{7}$ & Bases roughness(A) & roller & $X_{23}$ & inner raceway roughness & inner race \\
$X_{8}$ & Spherical runout(A) & roller & $X_{24}$ & $S_{\text {if }}($ flange) & inner race \\
$X_{9}$ & $D_{w}(\mathrm{~V})$ & roller & $X_{25}$ & roughness (flange) & outer race \\
$X_{10}$ & $\Delta 2 \Phi(\mathrm{V})$ & roller & $X_{26}$ & $K_{\mathrm{e}}$ & outer race \\
$X_{11}$ & Convexity $(\mathrm{V})$ & roller & $X_{27}$ & $S_{\mathrm{e}}$ & outer race \\
$X_{12}$ & Roundness $(\mathrm{V})$ & roller & $X_{28}$ & $\Delta 2 \alpha$ & outer race \\
$X_{13}$ & Waviness $(\mathrm{V})$ & roller & $X_{29}$ & $L_{\mathrm{e}}$ & outer race \\
$X_{14}$ & Roughness $(\mathrm{V})$ & roller & $X_{30}$ & outer raceway roundness & outer race \\
$X_{15}$ & Bases roughness $(\mathrm{V})$ & roller & $X_{31}$ & outer raceway waviness & outer race \\
$X_{16}$ & spherical runout(V) & roller & $X_{32}$ & outer raceway roughness & outer race \\
\hline & & & &
\end{tabular}

The remaining parameters affecting the measurement data are shown in Fig. 1

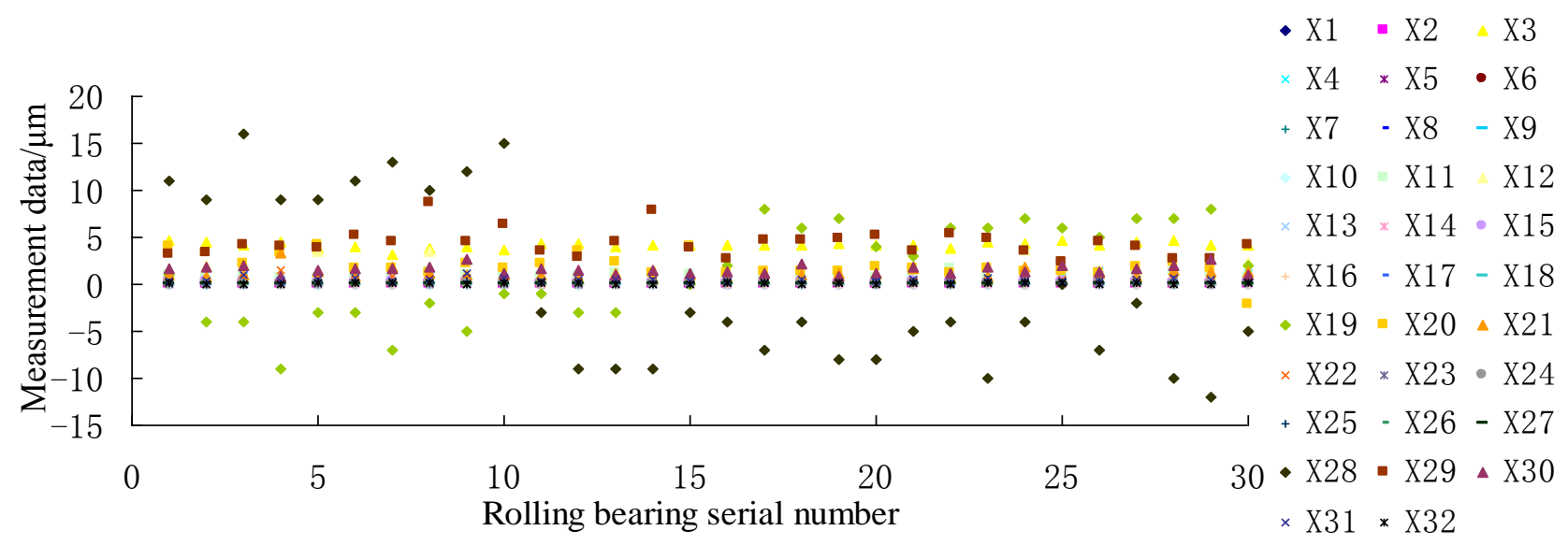

Figure 1. The parameter data of each parameter

In the analysis, the 32 factors were analyzed using the grey correlation degree analysis of grey system theory and the one linear regression analysis of classic statistics theory. By integrating the above two methods for data processing, the inherent relationship between various factors and bearing vibration acceleration values can be comprehensively analyzed. The main factors affecting bearing vibration acceleration are thus reasonably found, and the main factors affecting the bearing quality are obtained.

Correlation Analysis. In the process of grey correlation degree analyzing [10], define the vibration acceleration, $Y$, as the main sequence and the each factor, $X_{i}$, as the data sequence, take the 
value of resolution factor, $\xi$, as 0.5 . Take two different initialization operator, $D$, to analyze, and the results are shown in Table 2 . In the process of relative correlation degree analyzing, define the vibration acceleration, $Y$, as the main sequence and the each factor, $X_{i}$, as the subsequence, with the results shown in Table 2.

Table 2 Correlation sequence

\begin{tabular}{ccc}
\hline Number & Analytical & Correlation sequence(Top 10) \\
\hline 1 & Initialization & $X_{1} \succ X_{3} \succ X_{8} \succ X_{9} \succ X_{11} \succ X_{24} \succ X_{6} \succ X_{26} \succ X_{30} \succ X_{32}$ \\
2 & Equalization & $X_{3} \succ X_{1} \succ X_{8} \succ X_{23} \succ X_{7} \succ X_{6} \succ X_{11} \succ X_{24} \succ X_{9} \succ X_{30}$ \\
3 & Relative & $X_{32} \succ X_{11} \succ X_{24} \succ X_{14} \succ X_{25} \succ X_{21} \succ X_{1} \succ X_{9} \succ X_{6} \succ X_{16}$ \\
\hline
\end{tabular}

3 correlation sequences were obtained after calculation. The top 10 factors of each correlation sequence were compared, and the factors that are contained in all correlation sequences are chosen and studied as the main influence factors. According to the principle of qualitative integration, the main impact factors are

$$
\left(X_{1}, X_{6}, X_{9}, X_{11}, X_{24}\right)
$$

One Element Linear Analysis. Perform one element linear regression analysis of all the obtained experimental data, and establish a linear regression equation between $Y$ and $X_{i}$. Test the linear correlation of each linear regression equation, calculate the correlation coefficient $r$ for each equation, and determine its relevance. It can be known from the correlation coefficient threshold table that the correlation coefficient $r$ is 0.361 when $\alpha$ equals to 0.05 and $n$ is 30 . When $|r| \geq 0.361$, the factors are linear correlated, otherwise unrelated. The paper lists only relevant factors are listed in the paper. The results are shown in Table 3.

Table 3 Correlation of bearing vibration acceleration value and influencing factors

\begin{tabular}{cccc}
\hline Factors & The regression equation & The correlation coefficient & Correlation \\
\hline$X_{8}$ & $Y_{8}=49.244-555.611 X_{8}$ & -0.3931 & Related \\
$X_{16}$ & $Y_{16}=48.156-165.837 X_{16}$ & -0.5072 & Related \\
$X_{28}$ & $Y_{28}=46.840+6.066 X_{28}$ & 0.4948 & Related \\
\hline
\end{tabular}

It can be concluded from Table 3 that the parameters, $X_{8}, X_{16}$ and $X_{28}$, are linear correlated with the vibration acceleration, $Y$.

Through comprehensive analysis of the grey correlation analysis and one element linear analysis, it can be concluded that there are 8 main factors of the 32 influencing factors affecting the bearing vibration quality, which are shown as follows:

$$
\left(X_{1}, X_{6}, X_{8}, X_{9}, X_{11}, X_{16}, X_{24}, X_{28}\right)
$$

\section{Establish Regression Model}

Based on the above experimental results, the regression models between $Y$ and the 8 main influence factors are established, and the parameters are redefined, as shown in Table 4.

A new sequence, $X$, is obtained.

$$
X=\left(X_{1}, X_{2}, X_{3}, X_{4}, X_{5}, X_{6}, X_{7}, X_{8}\right)
$$

By using the above test data, the multiple linear regression equation is established and optimized. By using the Optimum experimental data modeling and optimization of computer systems to effect parameters for screening and the regression model were optimized. Optimization process principles 
is that excluded from the argument and re-establish a polynomial regression, polynomial for all new $F$-test to determine their significance and standard deviation of the regression equation derived effective analysis.

Table 430204 main factors bearing quality symbols and their meanings

\begin{tabular}{cccc}
\hline Symbol & Meaning & Symbol & Meaning \\
\hline$X_{1}$ & $D_{\mathrm{w}}(\mathrm{A})$ & $X_{5}$ & convexity (V) \\
$X_{2}$ & roughness (A) & $X_{6}$ & Spherical runout(V) \\
$X_{3}$ & Spherical runout(A) & $X_{7}$ & $S_{\text {if }}($ flange) \\
$X_{4}$ & $D_{\mathrm{w}}(\mathrm{V})$ & $X_{8}$ & $\Delta 2 \alpha$ \\
\hline
\end{tabular}

The model analysis results, including significance and standard deviation, of three or more factors are shown in Table 5.

Table 5 Model analysis results

\begin{tabular}{cccc}
\hline Number & Model & Significance & Standard deviation[dB] \\
\hline 1 & $Y=Y\left(X_{2}, X_{5}, X_{6}, X_{8}\right)$ & insignificant & 0.851 \\
2 & $Y=Y\left(X_{2}, X_{5}, X_{6}\right)$ & insignificant & 0.972 \\
3 & $Y=Y\left(X_{2}, X_{5}, X_{8}\right)$ & insignificant & 0.997 \\
4 & $Y=Y\left(X_{2}, X_{6}, X_{8}\right)$ & striking & 0.878 \\
5 & $Y=Y\left(X_{5}, X_{6}, X_{8}\right)$ & striking & 0.774 \\
6 & $Y=Y\left(X_{1}, X_{2}, X_{5}\right)$ & insignificant & 1.141 \\
\hline
\end{tabular}

It can be concluded that $X_{6}$ and $X_{8}$ are the most important influence factors, and $X_{2}$ and $X_{5}$ are main influence factors.

\section{Summary}

In this paper, by using the combined theory of the grey system theory and the classical statistics theory, the linear and non-linear correlation degree between the influencing factors and vibration acceleration value were measured, and factors related to the vibration acceleration values were thus obtained. Using the above two methods to data processing, can be more comprehensive analysis of the relationship between the bearing vibration and various influence factors, thus more reasonable to find the main factors affecting bearing vibration acceleration, and then get the main factors affecting the bearing quality.

The main factors affecting the bearing vibration quality are the roller spherical runout range, the outer raceway angle error, the average of roller roughness and the roller convexity range. Due to the controllable of these factors in machining processes, the control of finished bearing quality will come into reality in parts machining process.

\section{Acknowledgements}

This project is supported by National Natural Science Foundation of China (Grant Nos. 51075123, 50375011, and 50675011). 


\section{References}

[1] S. Abbasion, A. Rafsanjani, A. Farshidianfar and N. Irani: Mechanical Systems and Signal Processing, Vol. 21 (2007) No 7, p.2933.

[2] D. Jacek and Z. Radoslaw: Applied Acoustics, Vol. 77 (2014), p.195.

[3] J.D. Zheng, J.S. Cheng and Y. Yang: Mechanism and Machine Theory, Vol. 70 (2013), p.441.

[4] E.V. Zaretsky and E.V. Branzai: Tribology Transactions, Vol. 48 (2005) No 1, p.32.

[5] Z.Q. Yu and Z.G. Yang: Journal of Failure Analysis and Prevention, Vol. 11 (2011) No 2, p.158.

[6] S. Söchting, I. Sherrington, S.D. Lewis and E.W. Roberts: Wear, Vol. 260 (2006) No 11-12, p.1190.

[7] X.T. Xia: Research on Vibration and Noise of Rolling Bearing (National Defence Industry Press, China 2015).

[8] X.T. Xia, Z.Y. Wang and H. Chang: Journal of Aerospace Power, Vol. 20 (2005) No 2, p.250. (In Chinese)

[9] X.T. Xia and L. Zhang: Bearing, (2005) No 1, p.24. (In Chinese)

[10]P. Yu and K. Li: Microcomputer Applications, Vol. 27 (2011) No 3, p.29. (In Chinese) 